\title{
Mast cell CD30 ligand is upregulated in cutaneous inflammation and mediates degranulation-independent chemokine secretion
}

\author{
Marie Fischer, ${ }^{1,2}$ Ilkka T. Harvima, ${ }^{3}$ Ricardo F.S. Carvalho, ${ }^{1}$ Christine Möller, ${ }^{1}$ Anita Naukkarinen, ${ }^{4}$ \\ Gunilla Enblad, ${ }^{2}$ and Gunnar Nilsson'1
}

\begin{abstract}
${ }^{1}$ Department of Medicine, Karolinska Institutet, Stockholm, Sweden. ${ }^{2}$ Department of Oncology, Radiology, and Clinical Immunology, Uppsala University, Uppsala, Sweden. ${ }^{3}$ Department of Dermatology and ${ }^{4}$ Department of Pathology, Kuopio University Hospital, Kuopio, Finland.
\end{abstract}

\begin{abstract}
Mast cells are involved in many disorders where the triggering mechanism that leads to degranulation and/or cytokine secretion has not been defined. Several chronic inflammatory diseases are associated with increased mast cell numbers and upregulation of the TNF receptor family member CD30, but the role of elevated CD30 expression is poorly understood. Here we report what we believe to be a novel way to activate mast cells with CD30 that leads to degranulation-independent secretion of chemokines. CD30 induced a de novo synthesis and secretion of the chemokines IL-8, macrophage inflammatory protein-1 $\alpha$ (MIP-1 $\alpha$ ), and MIP-1 $\beta$, a process involving the MAPK/ERK pathway. Mast cells were found to be the predominant CD30 ligand-positive (CD30L-positive) cell in the chronic inflammatory skin diseases psoriasis and atopic dermatitis, and both CD30 and CD30L expression were upregulated in lesional skin in these conditions. Furthermore, the number of IL-8-positive mast cells was elevated both in psoriatic and atopic dermatitis lesional skin as well as in ex vivo CD30-treated healthy skin organ cultures. In summary, characterization of CD30 activation of mast cells has uncovered an IgE-independent pathway that is of importance in understanding the entirety of the role of mast cells in diseases associated with mast cells and CD30 expression. These diseases include Hodgkin lymphoma, atopic dermatitis, and psoriasis.
\end{abstract}

\section{Introduction}

The vast majority of mast cell research over the years has focused on the role of these effector cells in asthma and allergy, almost completely overlooking their contribution to acquired and innate immune responses beyond those mediated by IgE. This biased interest is due to the ability of mast cells to rapidly respond in a multifaceted fashion to IgE activation, releasing granule-stored preformed mediators, synthesizing lipid mediators, and producing cytokines and chemokines.

Over time, a more versatile role has been identified for these potent effector cells, highlighting the broad spectrum of functions that mast cells have in health and disease (1). For example, in innate immunity, mast cells act as a first line of defense against invading pathogens, in response to which they are activated through Toll-like receptors to release inflammatory mediators (2-4). Mast cells may also be critical for the onset and severity of autoimmune diseases (5). In a study by Lee et al., the development of antibody-induced inflammatory arthritis was shown to be mast cell dependent (6). Additionally, the observation (dating back to E. Westphal in 1891) that mast cells accumulate in tumor tissues has gained a renewed interest since it is now well accepted that interac-

Nonstandard abbreviations used: $\mathrm{AD}$, atopic dermatitis; $\mathrm{CBMC}$, cord bloodderived mast cell; CD30L, CD30 ligand; HL, Hodgkin lymphoma; HRS, Hodgkin and Reed-Sternberg (cells); MCP-1, monocyte chemoattractant protein-1; MIP-1 $\alpha$, macrophage inflammatory protein- $1 \alpha$; sCD30, soluble CD30.

Conflict of interest: The authors have declared that no conflict of interest exists. Citation for this article: J. Clin. Invest. 116:2748-2756 (2006). doi:10.1172/JCI24274. tions between inflammatory cells and tumor cells are important for tumorigenesis $(7,8)$. Although mast cells are clearly important in many pathophysiological states, disease-specific mast cell-triggering mechanisms apart from $\operatorname{IgE}$ are not well understood.

We have previously reported that the presence of an elevated number of mast cells in Hodgkin lymphoma (HL) is associated with poor prognosis (9). One characteristic of this lymphoma is high expression of CD30, a TNF receptor superfamily member, on malignant Hodgkin and Reed-Sternberg (HRS) cells. The corresponding CD30 ligand (CD30L, also known as CD153) is a type II transmembrane glycoprotein with an extracellular $C$ terminal domain that belongs to the TNF superfamily (10). Cells expressing $\mathrm{CD} 30 \mathrm{~L}$ can be found within the massive infiltrate of inflammatory cells seen in HL tumors. The interaction between CD30L-bearing cells and the $\mathrm{CD} 30^{+}$HRS cells they surround is believed to be important for tumor progression $(11,12)$. Intriguingly, mast cells are the predominant CD30L-expressing cells in affected lymph nodes in people with the malignancy. In fact, as many as two-thirds of the CD30L-bearing cells in these tumors are mast cells (13).

Although CD30 was originally identified as a surface marker on HRS cells in HL (14), it was subsequently found on malignant lymphocytes in various non-Hodgkin lymphomas and on activated T and B cells as well (15). CD30 was shown to be consistently expressed on a subset of lymphocytes known as Th2 cells (16), and accordingly, CD30 expression has been associated primarily with inflammatory disorders, such as atopic dermatitis (AD), that have a Th2 profile (17-19). However, it is now clear that Th1 and Th0 lymphocytes also express CD30 $(20,21)$, and the distinction 

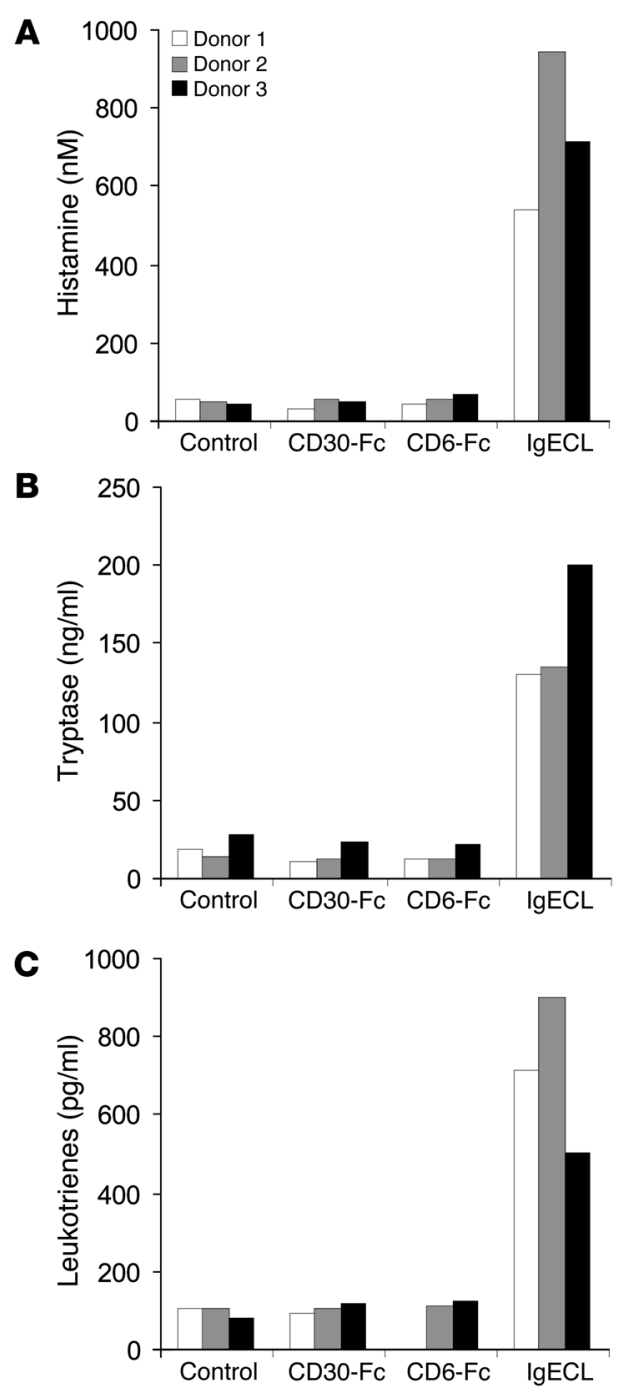

between Th1 and Th2 disorders based on CD30 expression is not absolute. For example, CD $30^{+} \mathrm{T}$ cells have been found in lesional skin in psoriasis, a chronic inflammatory disorder of the Th1 subtype (22). The contribution of cells expressing CD30L to the pathogenesis in chronic cutaneous inflammatory diseases such as $\mathrm{AD}$ and psoriasis is poorly understood. Despite the fact that mast cell numbers are elevated in lesional skin compared with healthy skin in both AD and psoriasis $(23,24)$, CD30L expression on skin mast cells has not been investigated.

Interaction between CD30 and CD30L affects not only the receptor-bearing cells. The induction of a reversed signaling pathway in which the ligand acts as a receptor and transmits a downstream signal has also been reported (25-27). The structure of CD30L with a $\mathrm{C}$ terminal extracellular domain and a short intracellular $\mathrm{N}$ terminal domain makes this interaction possible. By a previously unknown mechanism, the intracellular part of CD30L is capable of transducing downstream signals that lead to diverse effects, such as cytokine production. With the capacity of mast cells to produce a wide variety of inflammatory mediators, activation via CD30L may be a mechanism that explains mast cell involvement in CD30-associated disease.

In this study, we identified a mast cell activation pathway where CD30 treatment leads to specific chemokine production indepen-

\section{Figure 1}

Treatment of CBMCs with CD30-Fc does not lead to degranulation or synthesis of lipid-derived mediators. In vitro CBMCs $\left(1 \times 10^{5} \mathrm{cell} / \mathrm{ml}\right)$ from 3 different donors were stimulated for 30 minutes with CD30-FC $(10 \mu \mathrm{g} / \mathrm{ml}), \mathrm{CD} 6-\mathrm{Fc}(10 \mu \mathrm{g} / \mathrm{ml})$, or IgE cross-linking (IgECL). Culture medium was recovered by centrifugation and analyzed for the presence of (A) histamine, (B) tryptase, or (C) leukotrienes.

dent of degranulation. Moreover, we show that mast cells are the predominant CD30L-expressing cells in AD and psoriasis. This study provides what we believe are new insights into CD30L downstream signaling and mast cell involvement in CD30-associated disease.

\section{Results}

Absence of degranulation and leukotriene synthesis after CD30 activation of mast cells. Mast cell activation is often regarded as synonymous with degranulation and synthesis of lipid-derived mediators. Therefore we analyzed the release of histamine and tryptase stored in granules and measured the synthesis of leukotrienes after 30 of minutes activation of human cord blood-derived mast cells (CBMCs) with a CD30-Fc fusion protein. We used aggregation of the high-affinity IgE receptor as a positive control for activation and CD6-Fc as a negative control. As shown in Figure 1, CD30-Fc did not induce degranulation (Figure 1, A and B) or leukotriene synthesis (Figure $1 \mathrm{C}$ ). The cells responded to $\mathrm{IgE}$ receptor aggregation by releasing all of these mediators, as expected.

Characterization of cytokine and chemokine expression after CD30 activation. Because mast cells have the potential to produce a variety of cytokines upon stimulation, we next turned our focus to mRNA expression of inflammatory cytokines with known involvement in $\mathrm{HL}, \mathrm{AD}$, and psoriasis. After 3 hours activation with CD30-Fc, a strong upregulation of the chemokine $I L-8$ was observed using the RNase protection assay (RPA) (Figure $2 \mathrm{~A}$ ). In addition, $T N F-\alpha, I L-6$, and $I L-13$ mRNA expression were also upregulated, although not to the same extent. In contrast, $I L-12, I L-4$, and $I F N-\gamma$ mRNA expression were not induced after mast cell activation with CD30.

The pronounced expression of $I L-8$ led us to further investigate the effect of CD30-Fc activation on the induction of other chemokines. As shown in Figure 2B, activation of CBMCs with CD30 induced strong expression of the mRNAs for macrophage inflammatory protein-1 $\alpha$ (MIP-1 $\alpha), M I P-1 \beta$, and monocyte chemoattractant protein-1 (MCP-1) in addition to $I L-8$. CD30 activation also caused a slight induction of the mRNA for I-309. In contrast, CD30 activation caused no detectable increase in the expression of the mRNAs for lymphotactin, RANTES, or IFN- $\gamma$-inducible protein-10 (IP-10) (data not shown).

CD30 induces chemokine release. Upregulation of cytokine transcripts does not necessarily mean that elevated levels of cytokines will be released from the mast cells. To investigate whether the CBMCs actually released the cytokines upregulated at the mRNA level, we measured cytokine levels in the culture media 30 minutes and 24 hours after CBMC activation with CD30-Fc. No cytokine release was observed 30 minutes after activation, but after 24 hours, large amounts of secreted IL- 8 could be measured (Figure 2, C and D). The secretion of IL- 8 after 24 hours was not accompanied by release of histamine (data not shown). Similar results were obtained with IL-8 secretion when CBMCs were treated with plate-bound monoclonal anti-CD30L antibody (but not with the isotype control) or soluble CD30-Fc (sCD30-Fc) (data not shown). Of the other cytokines measured (IL-1 $\beta$, IL-4, IL-10, IL-12, IL-13, IFN- $\gamma$, and TNF- $\alpha$ ), only TNF- $\alpha$ showed a slight induction (data not shown). Consistent 

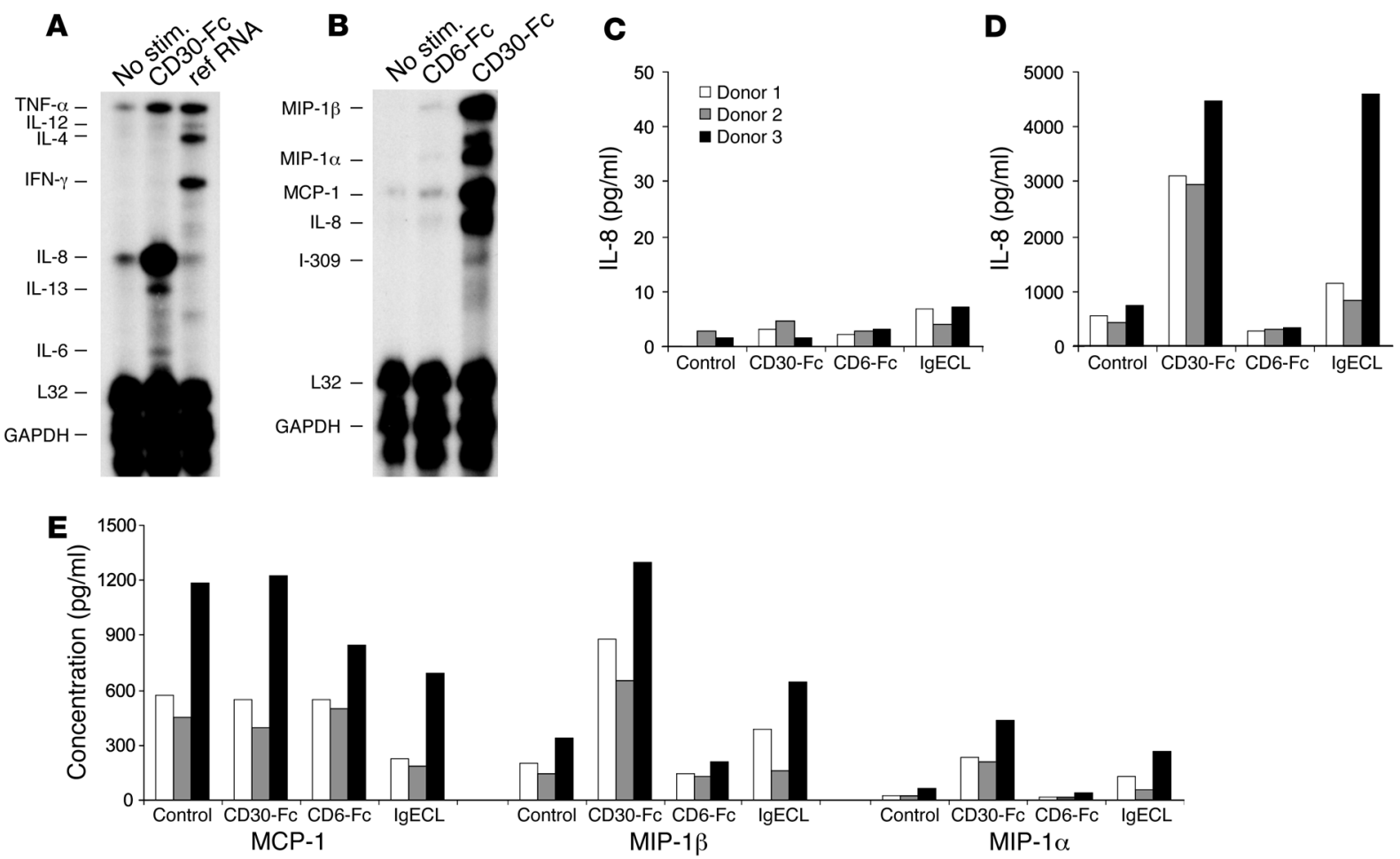

Figure 2

CD30-Fc stimulation of CBMCs induces chemokine expression. (A) CBMCs at a concentration of $2 \times 10^{5}$ cells $/ \mathrm{ml}$ were stimulated with $10 \mu \mathrm{g} / \mathrm{ml}$ of CD30-Fc, and total RNA was prepared. Expression of different cytokine mRNAs was analyzed after 3 hours of stimulation using RNase protection assay. A reference RNA (ref RNA) supplied by the manufacturer was also included. No stim., no stimulation. (B) CBMCs $\left(2 \times 10^{5} \mathrm{cells} / \mathrm{ml}\right)$ were stimulated with CD30-Fc or CD6-Fc $(10 \mu \mathrm{g} / \mathrm{ml})$ for 3 hours, and total RNA was prepared. Expression of different chemokines was analyzed by RNase protection assay. Data presented in $\mathbf{A}$ and $\mathbf{B}$ are from a single representative experiment out of 3 performed. CBMCs from 3 different donors were treated with CD30-Fc, CD6-Fc $\left(10 \mu \mathrm{g} / \mathrm{ml}, 1 \times 10^{5} \mathrm{cells} / \mathrm{ml}\right)$, or lgE cross-linking. Supernatants were recovered by centrifugation. Release of IL-8 was analyzed using ELISA after (C) 30 minutes and (D) 24 hours. (E) Secretion of chemokines was analyzed after 24 hours.

with the upregulation of chemokine mRNAs, we were able to detect an increase in the secreted levels of MIP-1 $\beta$ and MIP- $1 \alpha 24$ hours after activation. In contrast, MCP-1 had a high constitutive secretion, without further increase upon CD30 stimulation (Figure 2E). RANTES levels were barely detectable, and no increase in the release could be detected after CD30 stimulation (data not shown).

Given that CD30-Fc activation of CBMCs increased production of IL-8, we conducted a dose-response and kinetic analysis to quantify the effect. In the initial experiments, we used $10 \mu \mathrm{g} / \mathrm{ml}$ of CD30-Fc fusion protein, which proved to be the optimal concentration for IL-8 induction (Figure 3A). The level of IL-8 in the media increased in a time-dependent manner, reaching $3-5 \mathrm{ng} / \mathrm{ml}$ after 24 hours (Figure 3B). In contrast, the spontaneous release of IL-8 in the controls (without CD30 activation) did not increase with time (Figure 3C).

Our data indicate that a de novo synthesis of IL-8 occurs upon CD30 activation of CBMCs. In order to investigate this relationship further, we treated CD30-activated CBMCs with cycloheximide to inhibit protein synthesis. As shown in Figure 4, cycloheximide completely inhibited the secretion of IL-8. This result was not due to cell death since no effect on viability could be detected (data not shown). Thus, CD30L transmits a downstream signal leading to IL-8 protein production.

CD30 activates MAPK signaling pathways. Since nothing is known about downstream signaling by CD30L, we next investigated the effect of CD30 activation on the MAPK pathway, which is involved in the regulation of many cellular functions, including expression of cytokines. Treatment of CBMCs with CD30-Fc, but not CD6-Fc, induced phosphorylation of ERK 1/2 (Figure 5A), indicating an activation of the MAPK pathway.

Using various inhibitors, we further sought to study whether this pathway and/or others were involved in the CD30-mediated upregulation of IL-8 secretion. Inhibition of MEK (a kinase upstream of ERK) by PD98059 diminished the release of IL- 8 by 40\%. The PI3K inhibitors Wortmannin and LY294002 decreased IL-8 secretion by approximately $50 \%$ and $90 \%$, respectively. In contrast, SB203580, a p38-kinase inhibitor, did not affect IL-8 secretion (Figure 5B). These data support the involvement of the MAPK pathway and indicate a role for the PI3K pathway in IL-8 secretion after CD30 activation.

In vivo expression of $C D 30 L$ on mast cells in $A D$ and psoriasis. We have previously demonstrated that the number of tryptase-positive mast cells is higher in lesional compared with nonlesional skin in both $\mathrm{AD}$ and psoriasis $(23,24)$. Furthermore, we have shown that mast cells are the predominant CD30L-expressing cells in HL (13). However, the expression of CD30L in skin mast cells has not been investigated previously. In this study, histochemical staining showed that mast cells in the upper dermis and near the epidermis were immunoreactive to CD30L in both $\mathrm{AD}$ and psoriasis whereas mast cells in the mid and lower dermis were mostly devoid of CD30L immunore- 

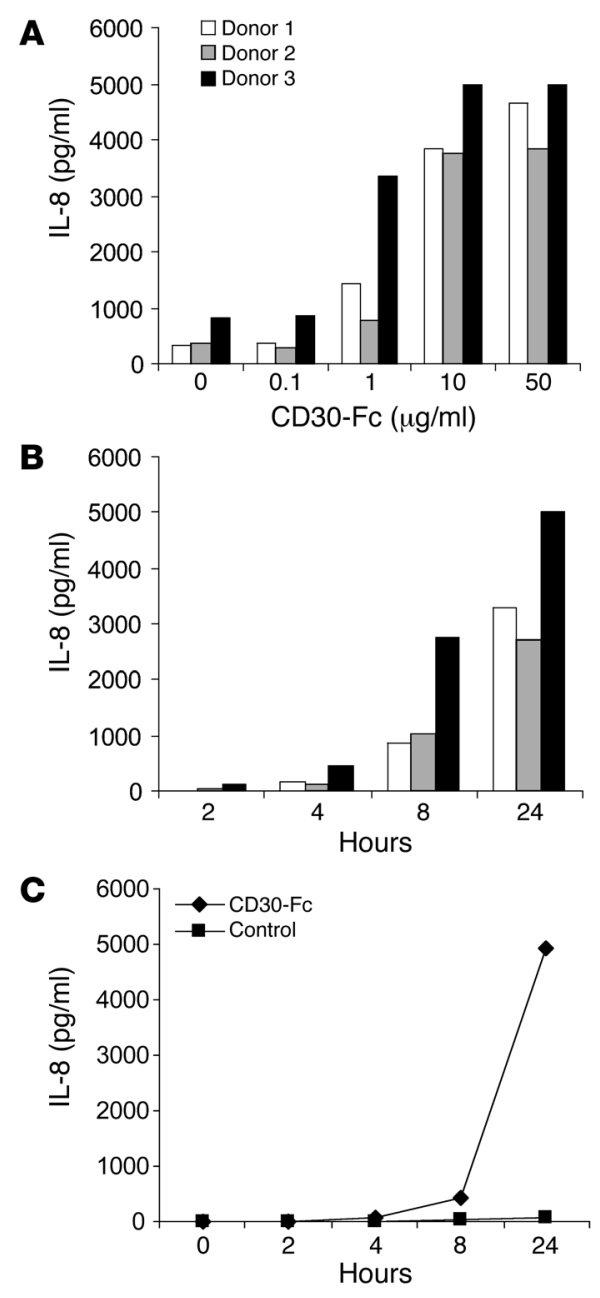

activity. Notably, mast cells were the predominant cell type in both $\mathrm{AD}$ and psoriatic lesions expressing CD30L (Figure 6).

As shown in Table 1, the percentage of CD30L-positive mast cells was significantly higher in lesional skin compared with healthylooking skin (54\% versus 34\%) in people with $\mathrm{AD}$, suggesting that CD30L was upregulated in mast cells in AD. Although fewer mast cells are CD30L positive in healthy-looking skin in psoriasis patients (8\%), a similar upregulation of CD30L expression was seen in mast cells in lesional psoriatic skin (33\%).

The number of CD30L-positive mast cells increased from $37 \pm 19$ cells $/ \mathrm{mm}^{2}$ to $70 \pm 26$ cells $/ \mathrm{mm}^{2}$ in healthy versus lesional AD skin compared with an increase from $5.5 \pm 5.9$ cells $/ \mathrm{mm}^{2}$ to $46 \pm 39$ cells $/ \mathrm{mm}^{2}$ in psoriasis. The number of CD30L-positive mast cells was lower in healthy-looking psoriatic skin compared with that of healthy controls (Table 1).

According to our previous results with this biopsy material (23, 24), the number of tryptase-positive mast cells in lesional and nonlesional AD skin is approximately $129-142$ cells $/ \mathrm{mm}^{2}$ and $102-120$ cells $/ \mathrm{mm}^{2}$, respectively. However, the difference is not significant. In the skin of patients with psoriasis, the number of tryptase-positive cells increased significantly from $65 \pm 33$ cells/ $\mathrm{mm}^{2}$ in healthy-looking skin to $120 \pm 55$ cells $/ \mathrm{mm}^{2}$ in lesional skin ( $P=0.002$; paired 2-tailed Student's $t$ test).

Expression of $C D 30$ in $A D$ and psoriasis. Although expression of CD30 has mainly been associated with Th2-related diseases such

\section{Figure 3}

CD30-Fc induces IL-8 secretion in a time- and dose-dependent manner. (A) Amount of IL-8 present in supernatant 24 hours after activation of CBMCs $\left(1 \times 10^{5}\right.$ cells $\left./ \mathrm{ml}\right)$ with different concentrations of CD30-FC $(0,0.1,1,10$, and $50 \mu \mathrm{g} / \mathrm{ml})$. (B) Kinetics of IL-8 secretion in response to $10 \mu \mathrm{g} / \mathrm{ml}$ of CD30-Fc was measured at 4 different time points (2, 4,8 , and 24 hours). (C) Spontaneous release of IL-8 from untreated CBMCs compared with CD30-Fc-treated cells. Data presented were derived from a single representative experiment out of 3 performed.

as $\mathrm{AD}$, Table 1 shows that CD30-positive cells were also detected in psoriasis, a Th1-related disease. In both diseases, an increase in the number of CD30-expressing cells was observed in lesional skin. As was the case with CD30L, the CD30-expressing cells were also predominantly concentrated in the uppermost dermis in both diseases. These cells appeared to reach deeper in the dermal layers in lesional skin from $\mathrm{AD}$ versus psoriasis patients. Based on localization and morphology, the CD30-expressing cells were most likely T cells. No correlation (Spearman's correlation test) was observed between the number of CD30-positive cells and the percentage of CD30L-positive mast cells in the nonlesional and lesional skin of both skin diseases. Thus, CD30L expression by mast cells and CD30 expression on other cell types appear not to be closely related.

In order to find out whether mast cells express CD30, we stained 10 specimens from lesional $\mathrm{AD}$ skin and 5 specimens from lesional psoriasis skin for the marker. After photography, we restained the sections for tryptase. No colocalization of CD30 and tryptase was observed in the same cells.

Coexpression of tryptase and IL-8 in inflamed tissues. Theoretically, if CD30 activation leads to an upregulation of IL-8 expression by mast cells in vivo, the number of IL-8-expressing mast cells should be higher in areas with a higher expression of CD30, i.e., the upper dermis. To test this hypothesis, we compared the number of IL-8-expressing mast cells in the uppermost dermis of both healthy-looking skin and lesional skin from patients with $\mathrm{AD}$ and psoriasis. Staining revealed that the percentage of IL-8-expressing mast cells was higher in lesional skin of psoriasis compared with healthy-looking skin (Figure 7, A-D). This relationship also occurred in $\mathrm{AD}$. In fact, skin from 5 of 6 psoriasis patients and from 5 of $6 \mathrm{AD}$ subjects exhibited an upregulation of IL-8-express-

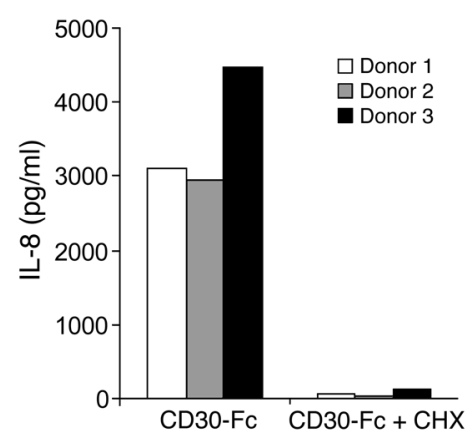

Figure 4

Induced IL-8 secretion is due to de novo synthesis. Levels of IL-8 present in supernatants from CBMCs $\left(1 \times 10^{5}\right.$ cells $\left./ \mathrm{ml}\right)$ after 24 hours treatment with CD30-Fc $(10 \mu \mathrm{g} / \mathrm{ml})$. Stimulation was conducted with or without the presence of the protein synthesis inhibitor cycloheximide $(\mathrm{CHX})(50 \mu \mathrm{M})$. 
A

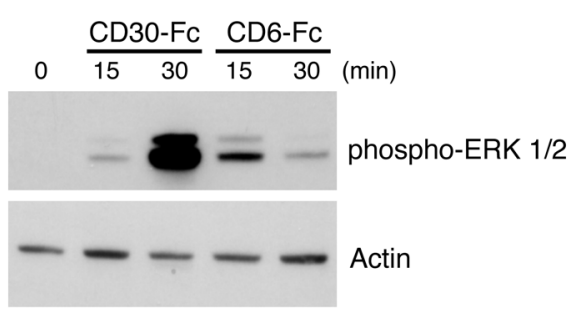

B

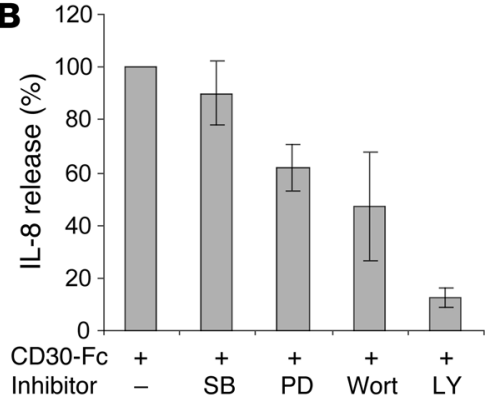

Figure 5

Signaling downstream CD30L involves MAPK and PI3K pathways in CBMCs. (A) CBMCs were activated with CD30-FC or CD6-Fc for 15 and 30 minutes, and phosphorylation of ERK (1/2) was measured by Western blot. (B) Effects of p38 inhibitor SB203580 (SB), MEK inhibitor PD98059 (PD), and PI3K inhibitors Wortmannin (Wort) and LY294002 (LY) on IL-8 secretion upon CD30-Fc treatment were analyzed by ELISA. Results are presented as percentage of control (no inhibitor) \pm SEM, $n=3$. ing mast cells in lesional skin compared with healthy-looking skin (Figure 7, E and F). This implies that CD30 activation induces upregulation of IL-8 expression in mast cells in inflamed skin.

Upregulation of IL-8 in skin mast cells after CD30 stimulation ex vivo. In order to clarify the relevance of IL-8 induction by CD30-Fc in mast cell cultures, we studied the effect of CD30-Fc in skin organ cultures ex vivo. Fresh skin punch biopsies from 3 healthy donors were cultured in diluent control, $100 \mu \mathrm{g} / \mathrm{ml} \mathrm{CD6-Fc}$, or $100 \mu \mathrm{g} / \mathrm{ml}$ CD30-Fc for 2 days. Thereafter, the skin specimens were processed to obtain cryosections, stained for tryptase enzyme-histochemically, and then stained for IL-8 immunohistochemically (Figure 8, $\mathrm{A}$ and $\mathrm{B})$. The number of tryptase-positive cells in control, CD6-Fc, and CD30-Fc skin cultures was $75 \pm 9,92 \pm 36$, and $95 \pm 19$ cells/ $\mathrm{mm}^{2}$, respectively (no significant difference). However, the number of IL-8-positive cells was $34 \pm 5,29 \pm 12$, and $56 \pm 8$ cells $/ \mathrm{mm}^{2}$ (Figure $8 \mathrm{C}$ ). Using the sequential double-staining method, we found all IL-8-immunopositive cells detected in stained skin sections to be tryptase positive. This strongly suggests that CD30-Fc can induce IL-8 production in mast cells ex vivo.

\section{Discussion}

This study identified CD30L signaling as a novel way to activate mast cells, leading to de novo synthesis of chemokines without the release of preformed granule mediators or de novo synthesis of leukotrienes.

Traditionally, mast cells have been considered effector cells in IgE-associated immune responses, such as asthma and allergy. Upon antigen cross-linking of $\operatorname{IgE}$ bound to the high-affinity IgE receptor, mast cells are activated to secrete diverse preformed mediators and to synthesize lipid-derived mediators and cytokines. However, recent work has shown that mast cells can be activated through various pathways, and because of the wide variety of mediators they can produce, we now know their role includes additional regulatory functions in both innate and acquired immunity (28). For example, activation of mast cells through Toll-like receptors and the subsequent degranulationindependent release of proinflammatory mediators are believed to be of importance in host defense against various pathogens (29). Another example is in a Th2-cytokine milieu, where cysteinyl leukotrienes can stimulate IL-4-primed CBMCs to generate cytokines independent of exocytosis (30).

Our results support such an expanded role for mast cells, since treatment of CBMCs with a CD30-Fc fusion protein did not lead to degranulation or production of leukotrienes but rather to a de novo synthesis of chemokines. This result implies that mast cell activation through CD30L can result in late-phase effects with leukocyte infiltration that support chronic disease development. The upregulation of CD30 expression in tumors and chronic inflammatory disorders (18) and the recent reports showing the importance of mast cells in the development of chronic autoimmune diseases also support this theory $(6,31)$.

We have reported previously that mast cells are the predominant CD30L-expressing cells in HL tumors (13), tumors characterized by a cytokine and chemokine profile that preferentially recruits Th2-type T cells and suppresses Th1-type responses (32). Here we have shown the same dominance of CD30L expression by mast cells in $\mathrm{AD}$ and psoriasis, 2 chronic cutaneous inflammatory disorders. Our data also indicate that the percentage of CD30L-positive mast cells increases in lesions of both diseases. Acute lesions in AD are characterized by Th2 cell infiltrates, but in more advanced AD lesions, a switch seems to occur to a heterogeneous population of Th 1 and Th 2 or Th 0 cells (33). In contrast, psoriasis is regarded as a Th1-driven reaction $(34,35)$. Accordingly, mast cell expression of CD30L seems to be independent of Th subtype. In a similar
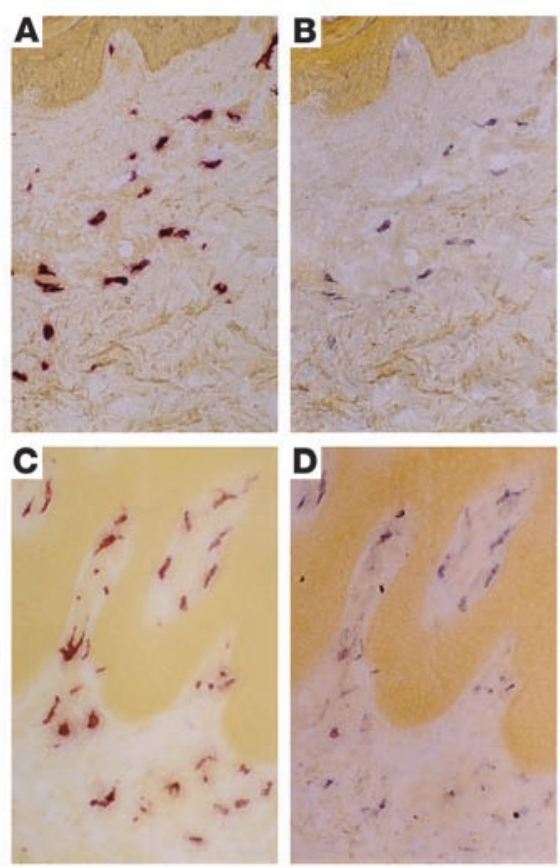

\section{Figure 6}

Mast cells express CD30L in AD and psoriasis. Tissue cryosections from (A) lesional AD and (C) psoriatic skin were enzyme-histochemically stained for tryptase. After photography, sections were restained with a monoclonal antibody for CD30L and rephotographed. Results for (B) lesional AD and (D) psoriatic skin are shown. Magnification, $\times 66$. 


\section{Table 1}

Percentage and number of CD30L-positive mast cells and total number of CD30-positive cells in upper dermis of skin from subjects with AD or psoriasis

\begin{tabular}{lcccccc} 
& \multicolumn{4}{c}{ Healthy-looking skin } & \multicolumn{2}{c}{ Lesional skin } \\
& \multicolumn{1}{c}{ CD30L-positive mast cells } & CD30-positive cells & CD30L-positive mast cells & CD30 positive cells \\
& $\%$ & cells/mm ${ }^{2}$ & cells/mm² & $\%$ & cells/mm ${ }^{2}$ & cells/mm $^{2}$ \\
AD & $34 \pm 20$ & $37 \pm 19$ & $48 \pm 51$ & $54 \pm 16^{\mathrm{A}}$ & $70 \pm 26^{\mathrm{A}}$ & $298 \pm 160^{\mathrm{B}}$ \\
Psoriasis & $8 \pm 11$ & $5.5 \pm 5.9$ & $13 \pm 16$ & $33 \pm 21^{\mathrm{B}}$ & $46 \pm 39^{\mathrm{A}}$ & $269 \pm 129^{\mathrm{B}}$ \\
Normal skin & $30 \pm 10$ & $38 \pm 18$ & $11 \pm 8$ & & &
\end{tabular}

Results are expressed as mean $\pm \mathrm{SD}$ ( $n=10$ in the case of AD and psoriasis and $n=9$ in the case of normal skin). $P$ values were determined using a paired 2-tailed Student's $t$ test when comparing values in lesional skin with corresponding values in healthy-looking skin. ${ }^{A} P=0.005$; ${ }^{B} P<0.001$.

indiscriminate manner, the number of CD30-expressing cells is higher in lesional skin from both patients with AD and patients with psoriasis. This finding strongly supports the conclusion that CD30 cannot be considered a specific marker of Th2 cells.

Cells expressing CD30L and those positive for CD30 were, in our study, present mainly in the same area in the upper dermis in both psoriatic lesions and AD lesions. This morphological feature makes interactions between CD30- and CD30L-positive cells possible. In this context, the recent finding that mast cells are stimulated to produce IL- 8 by T cells via an unknown mechanism is interesting (36). However, direct cell-cell contact is not necessary to affect cells via CD30L since the extracellular part of membrane-bound CD30 can be cleaved by metalloproteinases to produce sCD30 (37). In addition to $\mathrm{HL}$ and $\mathrm{AD}$, many other conditions are associated with elevated sCD30 levels. Epstein-Barr virus infections, systemic lupus erythematosus, systemic sclerosis, rheumatoid arthritis, and Graves disease are examples (18). Mast cells are present in several of these CD30-associated diseases and may be important for their pathogenesis. Therefore, one could speculate that a similar activation mechanism for mast cells exists in these disorders, leading to common features such as recruitment of inflammatory cells.

CD30L has a cytoplasmic tail consisting of 37 amino acids conserved between species, a feature that makes signal transduction feasible. Examples of such so-called reverse signaling have been shown for various TNF family members, including CD40 ligand, OX40 ligand, and Fas ligand (38-40). Signaling downstream of $\mathrm{CD} 30 \mathrm{~L}$ is reported to induce proliferation of and IL- 6 production by T cells, IL-8 production and oxidative burst in neutrophils (25), and impaired immunoglobulin isotype switching in B cells (26). Here we report CD30-induced reverse signaling and secretion of chemokines by mast cells. These results extend our understanding of downstream signaling by identifying a new cell type capable of responding to CD30 stimulation. Furthermore, our data indicate that signaling via CD30L and subsequent IL-8 release involve the MAPK pathway and possibly also the PI3K pathway. These are the first reported data, to our knowledge, to describe this mechanism. However, further studies are required to elucidate more details about the downstream events.

The presence of IL-8 in AD and psoriasis has been documented $(41,42)$, and a correlation between mast cell density and IL-8 expression in psoriasis has also been reported (43). Using sequential staining, we were able to show that mast cells are the most likely source of IL-8 in both AD and psoriasis. Our findings that (a) mast cells are the predominant CD30L-expressing cell in $\mathrm{AD}$ and psoriasis, (b) the expression of CD30 in other cells increases in lesional skin of these 2 diseases, (c) there is an increase in IL-8-

\section{Figure 7}

Upregulation of IL-8-positive mast cells in lesional skin from patients with $A D$ or psoriasis. Tissue sections from (A) psoriatic healthy-looking and (C) lesional skin were first enzyme-histochemically stained for tryptase. After photography, sections were restained with a polyclonal antibody to IL-8. Results for (B) psoriatic healthy-looking and (D) lesional skin are shown. Percentages of IL-8expressing mast cells in healthy-looking and lesional skin were determined for $(E) 6$ AD subjects and $(F) 6$ psoriatic subjects. Magnification, $\times 66$.
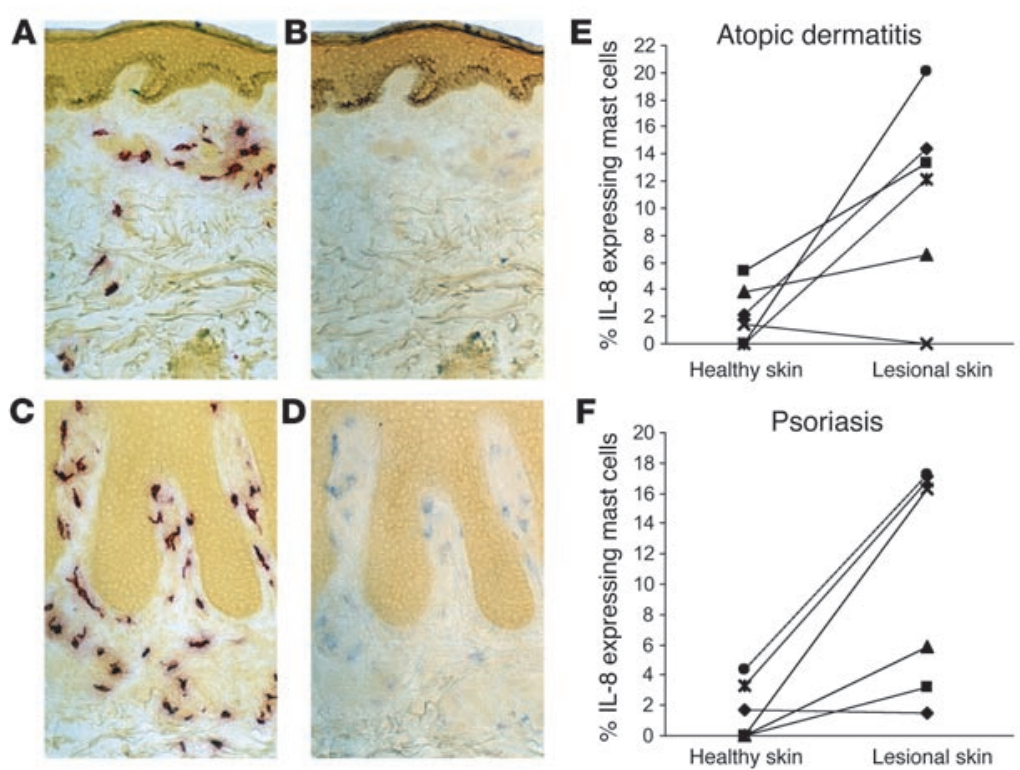

F

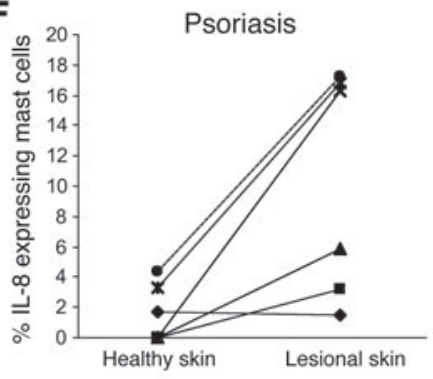



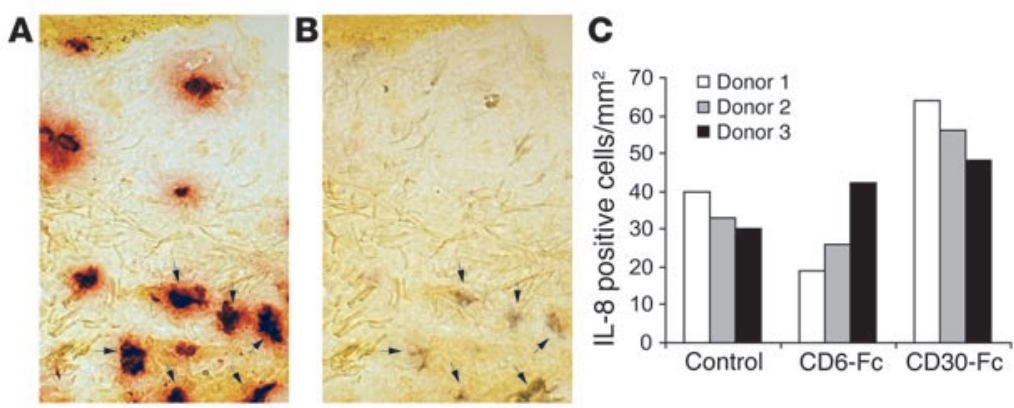

Figure 8

Increase in IL-8 expression in healthy skin mast cells after CD30-Fc stimulation of skin biopsies ex vivo. Punch biopsies from 3 donors were subjected to submerged skin organ culture. Diluent control, $100 \mu \mathrm{g} / \mathrm{ml} \mathrm{CD6-Fc,} \mathrm{or} 100 \mu \mathrm{g} / \mathrm{ml}$ CD30-Fc was added to the culture. After 2 days in culture, skin specimens were processed for cryosections. (A) Sections were first enzyme-histochemically stained for tryptase. (B) After photography, sections were restained with a polyclonal antibody to IL-8. Arrows indicate cells that are positive for both tryptase and IL-8. (C) Number of IL-8 positive cells present after 2 days in culture was analyzed. Results are presented as number of IL-8 positive cells $/ \mathrm{mm}^{2}$. Magnification, $\times 66$.

positive mast cells in $\mathrm{AD}$ and psoriasis, and (d) CD30 treatment of mast cells in vitro and ex vivo induces IL-8 expression together suggest that engagement of CD30L on mast cells results in induced production of IL-8 in vivo.

A prerequisite for the development of chronic inflammatory diseases such as AD and psoriasis (as well as tumor maintenance in $\mathrm{HL}$ ) is the recruitment of inflammatory cells, a process often regulated by chemokines (44). Many different chemokines, including IL-8, have been shown to be induced in these diseases $(45,46)$. In addition to IL-8, we observed increased expression and secretion of several other chemokines after CD30 stimulation of mast cells. Together, IL-8, MIP-1 $\alpha$, and MIP- $1 \beta$ are capable of recruiting most of the cell types (e.g., granulocytes, monocytes, and lymphocytes) found in lesional tissues of these diseases.

It is becoming evident that mast cells have a jack-of-all-trades role, contributing to the development of many pathological conditions, although the mechanisms of mast cell activation beyond $\operatorname{IgE}$ are largely unknown. Identification of a novel activation pathway via CD30L furthers our understanding of diseases (such as HL, $\mathrm{AD}$, and psoriasis) associated with mast cells and CD30 expression but not directly with IgE.

\section{Methods}

\section{Mast cell cultures}

CBMCs were obtained from umbilical cord blood as previously described $(47,48)$ and maintained in complete RPMI 1640 medium supplemented with $10 \%$ FCS, $50 \mathrm{ng} / \mathrm{ml}$ stem cell factor, and $10 \mathrm{ng} / \mathrm{ml} \mathrm{IL-6} \mathrm{(Amgen).} \mathrm{The}$ cells were cultured for 8-12 weeks and the medium exchanged once a week. Mast cell development was evaluated by staining for the mast cell-specific serine proteinase tryptase, as previously described (49). The purity of mast cells exceeded $95 \%$ when used in the activation experiments. The use of CBMCs in this study was approved by the ethics committee at Uppsala University Hospital. All donors gave informed consent.

\section{Measurements of mediator release}

For measurements of histamine, leukotrienes, and tryptase, CBMCs $\left(1 \times 10^{5}\right.$ cells $\left./ \mathrm{ml}\right)$ were placed in polystyrene cell culture plates pre- coated with $10 \mu \mathrm{g} / \mathrm{ml} \mathrm{CD} 30-\mathrm{Fc}(110 \mathrm{kDa})$ or CD6-Fc $(110 \mathrm{kDa})(\mathrm{R} \& \mathrm{D}$ Systems). The endotoxin level was less than $1 \mathrm{EU}$ per $1 \mu \mathrm{g}$. Alternatively, cells were activated with a monoclonal anti-CD30L antibody (M80, provided by Amgen) or an IgG2b isotype control. After $30 \mathrm{~min}$ utes and 24 hours of incubation, supernatants were harvested by centrifugation. As a positive control, CBMCs from the same donors, sensitized overnight with $\operatorname{IgE}$ $(1 \mu \mathrm{g} / \mathrm{ml})$, were cross-linked with anti-IgE antibodies $(2 \mu \mathrm{g} / \mathrm{ml})$, and supernatants were harvested by centrifugation after 30 minutes and 24 hours. Supernatants from nonactivated cells were also collected. All samples were frozen at $-20^{\circ} \mathrm{C}$ until analysis. Histamine levels were analyzed by a specific enzyme immunoassay kit having a sensitivity of $0.5 \mathrm{nM}$ (Immunotech, Beckman Coulter) and concentrations of leukotrienes were measured using Leukotriene C4/D4/E4 Biotrak EIA System with a sensitivity of $10 \mathrm{pg} / \mathrm{ml}$ (Amersham Biosciences), both according to the manufacturers' instructions. Tryptase was measured with UniCAP Tryptase (Pharmacia Diagnostics).

For detection of preformed and newly synthesized secreted cytokines, CBMCs were stimulated and supernatants harvested as above. Supernatants were collected after 2, 4, 8, and 24 hours for the kinetics study, and in the dose-response study, the concentration of CD30-Fc ranged from $0-50 \mu \mathrm{g} / \mathrm{ml}$. Cycloheximide $(50 \mu \mathrm{g} / \mathrm{ml})$ (Sigma-Aldrich) was added to block de novo synthesis of proteins. CD30-Fc-stimulated CBMCs were also cotreated with various inhibitors, and IL-8 levels in media were measured after 24 hours. Inhibitors and final concentrations were as follows: Wortmannin $(0.1 \mu \mathrm{M}), \mathrm{SB} 203580(10 \mu \mathrm{M})$, PD98059 $(20 \mu \mathrm{M})$, and LY294002 (50 $\mu \mathrm{M})$ (Calbiochem; EMD Biosciences).

The presence of IL-8, IL-1 $\beta$, IL-6, IL-10, TNF- $\alpha$, and IL-12p70 was analyzed with the Human Inflammation Cytometric Bead Array (BD Biosciences - Pharmingen). Levels of MCP-1, MIP-1 $\alpha$, MIP-1 $\beta$, RANTES, and IL-8 were measured using the Human Chemokine Kit II Cytometric Bead Array (BD Biosciences - Pharmingen). In some experiments, a commercially available ELISA was used to measure IL-8 levels, according to manufacturer guidelines (Human IL-8 CytoSets; Biosource International, Invitrogen).

\section{Measurements of cytokine and chemokine mRNA expression}

Total RNA was prepared from CBMCs after culturing $2 \times 10^{5}$ cells $/ \mathrm{ml}$ for 3 hours in CD30-Fc- or CD6-Fc-precoated cell culture flasks, using TriPure Isolation Reagent (Roche Diagnostics). Cytokine and chemokine expression was analyzed by RNase protection assay (RPA), using a custommade template set for cytokines (TNF- $\alpha, I L-12, I L-4, I F N-\gamma, I L-8, I L-13$, and $I L-6)$ and the human chemokine-5 (hCK-5) template set for chemokines (BD Biosciences - Pharmingen).

\section{Western blotting}

For Western blot analysis, CBMCs $\left(2 \times 10^{5}\right.$ cells $\left./ \mathrm{ml}\right)$ were stimulated with sCD30-Fc or CD6-Fc for 0,15 , and 30 minutes. After activation, the mast cells were lysed in $1 \times$ lysis buffer $(20 \mathrm{mM}$ Tris- $\mathrm{HCl}(\mathrm{pH} 7.5), 150 \mathrm{mM}$ $\mathrm{NaCl}, 1 \mathrm{mM} \mathrm{Na} 2$ EDTA, 1 mM EGTA, $1 \%$ Triton, $2.5 \mathrm{mM}$ sodium pyrophosphate, $1 \mathrm{mM} \beta$-glycerophosphate, $1 \mathrm{mM} \mathrm{Na} \mathrm{VO}_{3}, 1 \mu \mathrm{g} / \mathrm{ml}$ leupeptin, and $1 \mathrm{mM} \mathrm{PMSF}$ ) and sonicated on ice. The phosphorylation and/or the total amount of the proteins of interest was studied by Western immunoblotting using a NuPAGE Bis-Tris Western gel (Novex; Invitrogen). After electrophoresis, the proteins were electroblotted onto nitrocellulose membranes (Hybond ECL; GE Healthcare). After transfer, filters were blocked in Tris-buffered saline containing $5 \% \mathrm{w} / \mathrm{v}$ nonfat dry milk and $0.1 \%$ Tween 
20 (Sigma-Aldrich). Membranes were then incubated with primary antibody overnight at $4{ }^{\circ} \mathrm{C}$ and with HRP-conjugated secondary antibody for 1 hour at room temperature. The proteins were visualized using an enhanced chemiluminescence (ECL) system (LumiGLO; New England BioLabs) and exposure to a Hybond ECL film (GE Healthcare).

LumiGLO, HRP anti-rabbit antibody, and antibody against phospho-p44/p42 MAPK (Thr202/Tyr204) (ERK 1/2) were purchased from Cell Signaling Technology. HRP anti-actin was purchased from Santa Cruz Biotechnology Inc.

\section{Histochemical analysis in $A D$ and psoriasis}

Subjects and tissue preparations. Ten subjects ( 6 females and 4 males, aged 17-50 years) with acute or subacute $\mathrm{AD}$ and 10 subjects ( 3 females and 7 males, aged 22-60 years) with mild to moderate chronic psoriasis vulgaris volunteered to participate in this study. Punch biopsies $(4 \mathrm{~mm})$ were taken from untreated lesional skin and from healthy-looking skin at least $2 \mathrm{~cm}$ apart from the lesions and were immediately embedded in OCT compound (Sakura) and frozen for preparation of $5-\mu \mathrm{m}$-thick cryosections. Biopsies from the healthy-looking skin of 9 basal cell carcinoma patients were used as normal skin controls. The methods used in this study were approved by the ethics committee of Kuopio University Hospital. All subjects gave informed consent.

Immunohistochemical staining for $\mathrm{CD} 30 . \mathrm{CD} 30$ was identified using a mouse monoclonal anti-CD30 antibody (Dako) and the avidin-biotin-peroxidase $(\mathrm{ABC})$ technique using the VECTASTAIN Elite ABC kit (Vector Laboratories) (24). Unrelated mouse immunoglobulin was used as the control at the same concentration as the specific antibody.

Sequential double-staining method for the localization of CD30L and IL-8 in tryptase-positive mast cells. The method has been described previously in detail (24). Briefly, tryptase-positive mast cells were first stained using $1 \mathrm{mM}$ Z-Gly-Pro-Arg-4-methoxy-2-naphthylamide as the substrate (Bachem) and Fast Garnet GBC as the chromogen (Sigma-Aldrich). After photographing (magnification, $\times 66$ ) at 6 random sites per sample in the upper dermis lining the epidermis, the red azo dye was dissolved away with $15 \%$ Tween 20 overnight. Thereafter, the same sections were stained immunohistochemically using an anti-CD30L mAb (Genzyme Diagnostics or Immunex Inc.) or a rabbit anti-IL-8 pAb (MONOSAN) and the VECTASTAIN Elite ABC kit. The stainings were controlled by unrelated mouse and rabbit immunoglobulins, respectively. After rephotographing at exactly the same sites as the previous pictures, the positively stained cells were counted by comparing the photographs side by side.

The differences in mast cell numbers between lesional and nonlesional $\mathrm{AD}$ and psoriatic skin were evaluated using paired 2-tailed Student's $t$ test. $P$ values less than or equal to 0.005 were considered significant. Spearman's rank correlation was used to compare the number of CD30-positive cells and the percentage of CD30L-positive mast cells.

\section{Skin organ culture to study the effect of CD30-Fc on skin mast cells ex vivo}

Three punch biopsies ( $4 \mathrm{~mm}$ ) were taken from the non-sun-exposed healthylooking skin of the left arm or forearm of 3 donors ( 2 males, aged 45 and 30 years, and 1 female, aged 46 years). None of these subjects had any known skin disease, but 2 of them were atopic in respect to respiratory symptoms. The biopsies were cleaned from the subcutaneous fat, washed with DMEM medium, and then subjected to submerged skin organ culture using $10 \%$ fetal calf serum, DMEM, and penicillin-streptomycin as the medium (50). Diluent control, $100 \mu \mathrm{g} / \mathrm{ml} \mathrm{CD6-Fc,} \mathrm{or} 100 \mu \mathrm{g} / \mathrm{ml} \mathrm{CD} 30-\mathrm{Fc}$ was added to the culture, which was incubated for 2 days at $5 \% \mathrm{CO}_{2}$ and $37^{\circ} \mathrm{C}$. Higher CD6-Fc and $\mathrm{CD} 30-\mathrm{Fc}$ concentrations were used to ensure that these proteins could sufficiently diffuse into the skin specimens. After the 2-day cultivation, the skin specimens were used to prepare for $5-\mu \mathrm{m}$ cryosections. On the sections, tryptase was stained enzyme-histochemically and IL-8 immunohistochemically (as above), and the total number of cells was counted. In addition, the localization of IL-8 in tryptase-positive mast cells was confirmed in all specimens by using the sequential double-staining method.

\section{Acknowledgments}

The authors would like to thank Anne Koivisto and Agnetha Beinhoff for expert technical assistance, Leif Carlsson and Ann Östlund (Pharmacia Diagnostics $\mathrm{AB}$ ) for conducting the tryptase assay, and Amgen Inc. for providing SCF and IL-6. This study was supported by the Swedish Cancer Society; the Swedish Research Council - Medicine; the King Gustaf V 80-years foundation; the Ollie and Elof Ericsson Foundation; the Hans von Kantzow Foundation; the Konsul Th C Bergh Foundation; the Magnus Bergvall Foundation; the Ellen, Walter, and Lennart Hesselman Foundation; the Swedish Cancer and Allergy Fund; the Karolinska Institutet; and Kuopio University Hospital. R.F.S. Carvalho is supported by a Marie Curie Early Stage Research Training Fellowship of the European Union's Sixth Framework Programme under contract number 504926.

Received for publication December 21, 2004, and accepted in revised form July 18, 2006.

Address correspondence to: Gunnar Nilsson, Department of Medicine, Clinical Immunology and Allergy Unit, Karolinska Institutet, KS L2:04, SE- 17176 Stockholm, Sweden. Phone: 46-8-517-70205; Fax: 46-8-335724; E-mail: Gunnar.P.Nilsson@ki.se.
1. Nathan, C. 2002. Points of control in inflammation. Nature. 420:846-852.

2. Galli, S.J., Maurer, M., and Lantz, C.S. 1999. Mast cells as sentinels of innate immunity. Curr. Opin. Immunol. 11:53-59.

3. Supajatura, V., et al. 2002. Differential responses of mast cell Toll-like receptors 2 and 4 in allergy and innate immunity. J. Clin. Invest. 109:1351-1359. doi:10.1172/JCI200214704.

4. Marshall, J.S., King, C.A., and McCurdy, J.D. 2003. Mast cell cytokine and chemokine responses to bacterial and viral infection. Curr. Pharm. Des. 9:11-24.

5. Benoist, C., and Mathis, D. 2002. Mast cells in autoimmune disease. Nature. 420:875-878.

6. Lee, D.M., et al. 2002. Mast cells: a cellular link between autoantibodies and inflammatory arthritis. Science. 297:1689-1692.

7. Coussens, L.M., and Werb, Z. 2001. Inflammatory cells and cancer: think different! J. Exp. Med. 193:F23-F26.
8. Hanahan, D., and Weinberg, R.A. 2000. The hallmarks of cancer. Cell. 100:57-70.

9. Molin, D., et al. 2002. Mast cell infiltration correlates with poor prognosis in Hodgkin's lymphoma. Br. J. Haematol. 119:122-124.

10. Smith, C.A., et al. 1993. CD30 antigen, a marker for Hodgkin's lymphoma, is a receptor whose ligand defines an emerging family of cytokines with homology to TNF. Cell. 73:1349-1360.

11. Gruss, H.J., et al. 1996. CD30 ligand expression in nonmalignant and Hodgkin's disease-involved lymphoid tissues. Am. J. Pathol. 149:469-481.

12. Pinto, A., et al. 1996. Human eosinophils express functional CD30 ligand and stimulate proliferation of a Hodgkin's disease cell line. Blood. 88:3299-3305.

13. Molin, D., et al. 2001. Mast cells express functional CD30 ligand and are the predominant CD30Lpositive cells in Hodgkin's disease. Br. J. Haematol. 114:616-623.

14. Schwab, U., et al. 1982. Production of a monoclonal antibody specific for Hodgkin and Sternberg-Reed cells of Hodgkin's disease and a subset of normal lymphoid cells. Nature. 299:65-67.

15. Stein, H., et al. 1985. The expression of the Hodgkin's disease associated antigen $\mathrm{Ki}-1$ in reactive and neoplastic lymphoid tissue: evidence that Reed-Sternberg cells and histiocytic malignancies are derived from activated lymphoid cells. Blood. 66:848-858.

16. Del Prete, G., et al. 1995. CD30-mediated signaling promotes the development of human T helper type 2-like T cells. J. Exp. Med. 182:1655-1661.

17. Bengtsson, A., Holm, L., Back, O., Fransson, J., and Scheynius, A. 1997. Elevated serum levels of soluble CD30 in patients with atopic dermatitis (AD). Clin. Exp. Immunol. 109:533-537.

18. Horie, R., and Watanabe, T. 1998. CD30: expression and function in health and disease. Semin. Immunol. 10:457-470.

19. Caproni, M., et al. 1997. In vivo relevance of CD30 
in atopic dermatitis. Allergy. 52:1063-1070.

20. Hamann, D., et al. 1996. CD30 expression does not discriminate between human Th1- and Th2-type T cells. J. Immunol. 156:1387-1391.

21. Bengtsson, A., et al. 1995. Not only Th2 cells but also Th1 and Th0 cells express CD 30 after activation. J. Leukoc. Biol. 58:683-689.

22. Ferenczi, K., Burack, L., Pope, M., Krueger, J.G., and Austin, L.M. 2000. CD69, HLA-DR and the IL-2R identify persistently activated $\mathrm{T}$ cells in psoriasis vulgaris lesional skin: blood and skin comparisons by flow cytometry. J. Autoimmun. 14:63-78.

23. Ackermann, L., and Harvima, I.T. 1998. Mast cells of psoriatic and atopic dermatitis skin are positive for TNF-alpha and their degranulation is associated with expression of ICAM-1 in the epidermis. Arch. Dermatol. Res. 290:353-359.

24. Horsmanheimo, L., et al. 1994. Mast cells are one major source of interleukin-4 in atopic dermatitis. Br. J. Dermatol. 131:348-353.

25. Wiley, S.R., Goodwin, R.G., and Smith, C.A. 1996. Reverse signaling via CD30 ligand. J. Immunol. 157:3635-3639.

26. Cerutti, A., et al. 2000. Engagement of CD153 (CD30 ligand) by CD30+ T cells inhibits class switch DNA recombination and antibody production in human IgD+ IgM+ B cells. J. Immunol. 165:786-794.

27. Saraiva, M., Smith, P., Fallon, P.G., and Alcami, A. 2002. Inhibition of type 1 cytokine-mediated inflammation by a soluble CD30 homologue encoded by ectromelia (mousepox) virus. J. Exp. Med. 196:829-839.

28. Galli, S.J., Nakae, S., and Tsai, M. 2005. Mast cells in the development of adaptive immune response. Nat. Immunol. 6:135-142.

29. Marshall, J.S. 2004. Mast-cell responses to pathogens. Nat. Rev. Immunol. 4:787-799.

30. Mellor, E.A., Austen, K.F., and Boyce, J.A. 2002. Cysteinyl leukotrienes and uridine diphosphate induce cytokine generation by human mast cells through an interleukin 4-regulated pathway that is inhibited by leukotriene receptor antagonists. J. Exp. Med. 195:583-592.

31. Secor, V.H., Secor, W.E., Gutekunst, C.A., and Brown, M.A. 2000. Mast cells are essential for early onset and severe disease in a murine model of multiple sclerosis. J. Exp. Med. 191:813-822.

32. Poppema, S. 1989. The nature of the lymphocytes surrounding Reed-Sternberg cells in nodular lymphocyte predominance and in other types of Hodgkin's disease. Am. J. Pathol. 135:351-357.

33. Higashi, N., Bang, K., Gesser, B., Lund, M., and Thestrup-Pedersen, K. 2001. Cytokine expression of skin T-lymphocytes from patients with atopic dermatitis. Acta Derm. Venereol. 81:3-7.

34. Ackermann, L., et al. 1999. Mast cells in psoriatic skin are strongly positive for interferon-gamma. $\mathrm{Br}$ J. Dermatol. 140:624-633.

35. Uyemura, K., Yamamura, M., Fivenson, D.F., Modlin, R.L., and Nickoloff, B.J. 1993. The cytokine network in lesional and lesion-free psoriatic skin is characterized by a T-helper type 1 cell-mediated response. J. Invest. Dermatol. 101:701-705.

36. Salamon, P., Shoham, N.G., Gavrieli, R., Wolach, B., and Mekori, Y.A. 2005. Human mast cells release interleukin-8 and induce neutrophil chemotaxis on contact with activated T cells. Allergy. 60:1316-1319.

37. Hansen, H.P., et al. 1995. A zinc metalloproteinase is responsible for the release of CD30 on human tumor cell lines. Int. J. Cancer. 63:750-756.

38. van Essen, D., Kikutani, H., and Gray, D. 1995. CD40 ligand-transduced co-stimulation of T cells in the development of helper function. Nature. 378:620-623.

39. Stuber, E., Neurath, M., Calderhead, D., Fell, H.P., and Strober, W. 1995. Cross-linking of OX40 ligand, a member of the TNF/NGF cytokine family, induces proliferation and differentiation in murine splenic B cells. Immunity. 2:507-521.

40. Suzuki, I., and Fink, P.J. 1998. Maximal proliferation of cytotoxic $\mathrm{T}$ lymphocytes requires reverse signaling through Fas ligand. J. Exp. Med. 187:123-128.

41. Duan, H., et al. 2001. Interleukin-8-positive neutrophils in psoriasis. J. Dermatol. Sci. 26:119-124.

42. Hatano, Y., Katagiri, K., and Takayasu, S. 1999. Increased levels in vivo of mRNAs for IL-8 and macrophage inflammatory protein-1 alpha (MIP-1 alpha), but not of RANTES mRNA in peripheral blood mononuclear cells of patients with atopic dermatitis (AD). Clin. Exp. Immunol. 117:237-243.

43. Jiang, W.Y., Chattedee, A.D., Raychaudhuri, S.P., Raychaudhuri, S.K., and Farber, E.M. 2001. Mast cell density and IL-8 expression in nonlesional and lesional psoriatic skin. Int. J. Dermatol. 40:699-703.

44. Moser, B., Wolf, M., Walz, A., and Loetscher, P. 2004. Chemokines: multiple levels of leukocyte migration control. Trends Immunol. 25:75-84.

45. Nomura, I., et al. 2003. Distinct patterns of gene expression in the skin lesions of atopic dermatitis and psoriasis: a gene microarray analysis. J. Allergy Clin. Immunol. 112:1195-1202.

46. Maggio, E., et al. 2002. Chemokines, cytokines and their receptors in Hodgkin's lymphoma cell lines and tissues. Ann. Oncol. 13(Suppl. 1):52-56.

47. Nilsson, G., et al. 1996. Stem cell factor-dependent human cord blood derived mast cells express alpha- and beta-tryptase, heparin and chondroitin sulphate. Immunology. 88:308-314.

48. Saito, H., et al. 1996. Selective growth of human mast cells induced by Steel factor, IL-6, and prostaglandin E2 from cord blood mononuclear cells. J. Immunol. 157:343-350.

49. Harvima, I.T., Naukkarinen, A., Harvima, R.J., and Horsmanheimo, M. 1989. Enzyme- and immunohistochemical localization of mast cell tryptase in psoriatic skin. Arch. Dermatol. Res. 281:387-391.

50. Kivinen, P.K., Nilsson, G., Naukkarinen, A., and Harvima, I.T. 2003. Mast cell survival and apoptosis in organ-cultured human skin. Exp. Dermatol. 12:53-60. 